\title{
INOVAÇÃO EM EDUCAÇÃO AMBIENTAL: UM ESTUDO DE CASO SOBRE A TRILHA DOS SENTIDOS DO PARQUE ESTADUAL MATA DO LIMOEIRO
}

\author{
Alex Luiz Amaral Oliveira ${ }^{1}$ \\ Frederico Mendes de Carvalho² \\ Fernanda de Fátima Oliveira ${ }^{3}$ \\ Arnaldo Freitas de Oliveira Júnior ${ }^{4}$ \\ Simone Magela Moreira ${ }^{5}$
}

Resumo: A Educação Ambiental, voltada para conscientização dos indivíduos, contribui para a solução dos problemas ambientais atuais por meio da mudança de mentalidade e de posturas. A Trilha dos Sentidos, desenvolvida pelo Parque Estadual Mata do Limoeiro, foi criada como uma estratégia para as atividades de Educação Ambiental, como forma de despertar a importância da natureza e da conservação do meio ambiente. Com os olhos vendados e os pés descalços, o visitante entra na trilha, guiado por uma corda e descobre uma nova forma de perceber a floresta, estimulado pelos canais sensoriais, redescobrindo a natureza. Este texto descreve como o projeto reitera o uso das Unidades de Conservação como território de atividades práticas no contexto da educação, oferecendo recursos que propiciam atividades e o contato direto com o meio ambiente.

Palavras-chave: Unidade de Conservação; Sustentabilidade; Preservação. Ambiental

Abstract: Environmental Education, aimed at raising awareness among individuals, contributes to the solution of current environmental problems through a change in mentality and attitudes. The Senses Trail, developed by the Mata do Limoeiro State Park, was created as a strategy for environmental education activities, as a way to awaken the importance of nature and environmental conservation. Blindfolded and bare feet, the visitor enters the trail, guided by a rope and discovers a new way of perceiving the forest, stimulated by the sensory channels, rediscovering nature. This text describes how the project reiterates the use of Conservation Units as a territory for practical activities in the context of education, offering resources that provide activities and direct contact with the environment.

Keywords: Conservation Unit; Sustainability; Environmental Preservation.

\footnotetext{
${ }^{1}$ IFMG - Campus Bambuí. E-mail: alexbiopuc@yahoo.com.br, http://lattes.cnpq.br/5940941594653446

2 IFMG - Campus Bambuí. E-mail: fred@negrito.com.br, http://lattes.cnpq.br/900710058295594

3 PEML. E-mail: fernandaoliveira@gmail.com,

${ }^{4}$ IFMG - Campus Bambuí. E-mail: arnaldojun@gmail.com, http://lattes.cnpq.br/2754961037728092

${ }^{5}$ IFMG - Campus Bambuí. E-mail: Simone.moreira@ifmg.edu.br, http://lattes.cnpq.br/833944401817153
} 


\section{Introdução}

A questão ambiental é um dos temas mais estratégicos nos compromissos e tratados internacionais e seu fortalecimento tem como um dos principais motivos, os impactos do modelo de desenvolvimento adotado pelo capitalismo. Assim, esta agenda vem ganhando muita força no mundo moderno e preocupações relacionadas à sustentabilidade, especialmente em sua dimensão ambiental, como degradações, uso contínuo (e sem precedentes dos recursos naturais) e aumento do consumo ganham destaque (ONU, 1987) e influenciam ações e políticas do poder público e da iniciativa privada.

Como consequência do modelo de desenvolvimento adotado pela sociedade pós-moderna (BAUMAN, 2018), a questão ambiental deve ser refletida de forma multidisciplinar e complexa (MORIN, 2011) porque sobre ela há a intervenção de diversos processos e diferentes racionalidades nas quais percebe-se a busca por soluções urgentes para os dilemas apresentados. Nesse sentido, impõe-se à humanidade a necessidade se construir novos padrões de relacionamento com a natureza e seus recursos, o que repercute sobre o estilo de vida e de consumo, conformando novos pactos e influenciando a ética, a cultura, a dinâmica política e social, bem como a organização do espaço (CEZARE, 2009).

É neste contexto que a Educação Ambiental ganha destaque no dia a dia e tem nas Unidades de Conservação (especialmente, nos Parques) os ambientes privilegiados para ensino e construção de novos mindsets. De acordo com o artigo 1ํ da Política Nacional de Educação Ambiental (BRASIL, 1995) entende-se por Educação Ambiental

Os processos por meio dos quais o indivíduo e a coletividade constroem valores sociais, conhecimentos, habilidades, atitudes, e competências voltadas para a conservação do meio ambiente, bem de uso comum de povo, essencial à sadia qualidade de vida e sua sustentabilidade (BRASIL, p.35, 1999).

Assim, a Educação Ambiental possibilita a construção de ideias, valores e atitudes que são potenciais multiplicadores da mudança de comportamento das pessoas e é ferramenta de formação ética, por meio da sensibilização e visões diferenciadas sobre a natureza (ONU, 1972). Tal processo é amparado pelos mecanismos de ensino-aprendizagem, por meio do qual a interações possibilita a sensibilização como ferramenta educativa.

Neste contexto, atividades de ensino e recreativas, envolvendo diferentes recursos pedagógicos, vêm sendo propostas no âmbito da Educação Ambiental em unidades de conservação e mesmo nas salas de aula (KISHIMOTO, 2002). Porém, é bastante comum, o uso de recursos visuais (objetos, figuras, imagens) para a inserção dos conteúdos que, muitas vezes, 
dificultam a inclusão de crianças com deficiência visual ou/e uma experiência mais intimista e afetiva, que propicie uma aprendizagem sensível. A carência de material pedagógico e lúdico, adaptado para pessoas com deficiência ou mesmo de experiências marcantes que permita uma experimentação mais próxima do ambiente natural frequentemente conduz a um subdesenvolvimento da capacidade de percepção do sujeito quanto a importância do meio ambiente. Este fenômeno, entre pessoas com deficiência é agravado pelo isolamento que a dificuldade imposta pela limitação (seja do indivíduo ou dos métodos) impõe, pois dificulta as interações entre o PCD e outras pessoas sem deficiência (CAMARGO et al., 2008).

Por isso, uma das práticas que devem ser valorizadas nos contextos de educação - formal e não formal - é a oferta de recursos que propiciem o aprendizado conjunto, sobre a necessidade da preservação ambiental que valorize a percepção e sensibilização sobre o papel central da natureza para a vida. Além disso, tais dispositivos devem levar os indivíduos a uma reflexão sobre a complexidade e interconectividade dos ecossistemas, estimular a cooperação social, a apropriação do ambiente e o fortalecimento de uma outra experiência de ensino-aprendizagem, apoiada numa lógica autônoma, crítica (FREIRE, 1996 ) e que reforce o "bem comum", o diálogo e a democracia.

Respondendo a esta problemática e entendendo a educação como um processo permanente, no qual as pessoas adquirem conhecimentos, valores e experiências para atuar na resolução dos problemas ambientais no presente e no futuro, o Parque Estadual Mata do Limoeiro criou a "Trilha dos Sentidos", como uma atividade que propõe reflexão multidisciplinar na interação com o meio ambiente e sua importância. É inovadora ao propor novas formas de refletir sobre o meio ambiente e inclui a unidade de conservação no contexto privilegiado de promoção da Educação Ambiental. Esta perspectiva dialoga com Quijano (2007, p.188) para quem a inovação é uma "condição necessária para o desenvolvimento global da economia e da sociedade". Neste sentido, só pode haver desenvolvimento pleno, se houver sustentabilidade.

O Parque Estadual Mata do Limoeiro é uma Unidade de Conservação (UC), classificada como de proteção integral (BRASIL, 2000) e gerenciada pelo Instituto Estadual de Florestas, autarquia do governo do Estado de Minas Gerais. Está localizado na Serra do Espinhaço, em Ipoema, distrito da Zona rural, há $50 \mathrm{~km}$ do centro de Itabira. Sua área é de 2.056,7 ha e se insere num território de transição de biomas com fragmentos de Mata Atlântica e Cerrado. No perímetro do Parque já foram identificadas espécies da fauna e flora ameaçadas de extinção como samambaiaçu, o jacarandá-caviúna e a braúnapreta, o rato do mato, o macaco bugio, o gambá-de-orelha-branca. Possui, ainda, muitos atrativos: cachoeiras, corredeira, mirantes, grutas e cânions. 
O Parque é reconhecido nacionalmente pelo trabalho de Educação Ambiental ${ }^{6}$, tendo hoje mais de 30 inciativas na área (IEF, 2018). A Trilha dos Sentidos é apenas um dos projetos e tornou-se, em 2016, um importante atrativo oferecido pelo parque aos seus visitantes. A "Trilha dos Sentidos" localiza-se em uma área natural, próxima a sede administrativa da unidade, facilitando o acesso de indivíduos com e sem deficiência.

Inicialmente, a atividade foi planejada para crianças moradoras do entorno, oferecendo apoio às escolas da região. Atualmente, contudo, recebe visitante de diferentes faixas etárias e de várias regiões do Brasil e do exterior e possibilita aos participantes uma experiência acessível, por meio da exploração dos sentidos de uma forma peculiar, imaginária, e intimista, levando-os ao resgate de lembranças, sensações e estímulos de forma individualizada, incorporando assim, diversos valores emanados dos serviços ambientais providos pelo parque. $\mathrm{A}$

Este texto objetiva discutir a atividade, apresentando sua estrutura e refletindo, a partir de observação dos pesquisadores, como os participantes reagem às diversas situações a que são expostos no percurso da atividade.

\section{Instrumentos e métodos}

Esta é uma pesquisa descritiva primária, realizada por meio de pesquisa participativa, na modalidade de participação observante. Thiollent (2003) a define como uma pesquisa social com base empírica, realizada em associação com uma problemática coletiva. Pesquisadores e participantes da pesquisa estão envolvidos de modo participativo e cooperativo na implementação, intervenção e análise de seus resultados.

\section{Discussão}

A "Trilha dos Sentidos" foi estruturada em uma pesquisa-ação, na qual se desenhou um percurso com características específicas. Em sua construção contou com a participação multidisciplinar de uma psicóloga, um biólogo e uma técnica ambiental. Após testes iniciais, foi aperfeiçoada e hoje é um dos principais constituintes da política de Educação Ambiental desenvolvida pelo Parque Estadual Mata do Limoeiro.

A experiência tem duração de aproximada de 75 minutos. Os participantes percorrem vendados, quase todo o trajeto de $100 \mathrm{~m}$, que é dividido em três estágios. É possível exercitar o tato, o olfato, o paladar e a audição. Eles são explorados como o auxílio dos monitores que acompanham o grupo. No início do percurso, a "Trilha dos Sentidos" pode provocar uma certa insegurança e temor, especialmente pelos visitantes videntes. Caminhar com

${ }^{6}$ Duas indicações e uma estatueta do prêmio Hugo Werneck, considerada a premiação ambiental mais importante da América Latina. Recebeu 3 troféus da SOS Natureza em reconhecimento aos serviços prestados ao meio ambiente. 
os olhos vendados gera certa ansiedade que é rapidamente vencida, e os participantes se adaptam, expressando-se mais confiantes e perceptivos. Isso porque embora a visão seja uma importante via de informação para o sujeito, obviamente não é a única. Outros sistemas fornecem informações sobre a orientação espacial, o movimento e o equilíbrio, possibilitando a percepção de posição, da direção do vento, da velocidade do movimento e orientação do corpo.

A experiência estimula o uso dos sentidos que são pouco exercitados no cotidiano por serem suprimidos por informações visuais. Na atividade ainda, são disponibilizados recursos materiais adequados ao conhecimento tátilcinestésico, auditivo, olfativo e gustativo. Assim, a vedação dos olhos permite uma atividade democrática, pois um deficiente visual tem acesso às mesmas informações que as outras pessoas (Figura 1). Todos os participantes são, portanto, estimulados a perceber o Parque por vias sensoriais diferentes da visão, aguçando os sentidos e as interações com o meio.

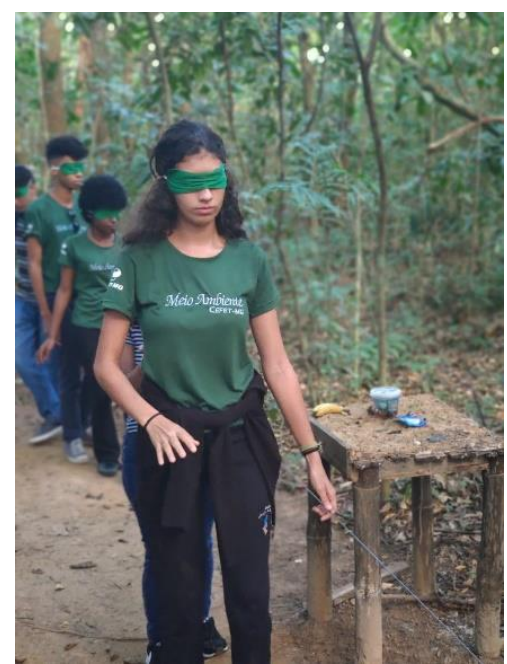

Figura 1: Participante vendada

Fonte: Arquivo do Parque, 2019.

No primeiro estágio, ao iniciar a trilha, os participantes são levados ao início do percurso onde está disposta uma corda que os guiará por todo o trajeto, permanecendo acompanhados pelos monitores do Parque. Logo no início, uma subida de sete degraus simboliza os anos iniciais da vida e os monitores propõem uma reflexão sobre as primeiras dificuldades inerentes ao descobrimento e aperfeiçoamento dos sentidos.

Posteriormente, são explorados o tato, olfato e o paladar (Figura 2). Para isso, os monitores do Parque levam até as mãos dos participantes itens da natureza como água, galhos, pedras (tato), tronco de árvores (tato), folhas secas (tato e olfato), mel (olfato e paladar), folhas de couve (olfato, paladar e tato), banana (olfato e paladar), rapadura (olfato e paladar), suco do limão (olfato e paladar), pó de café (olfato) e por fim cebola ou alguma outra fruta picada (olfato e paladar). As diferentes formas, cheiros e texturas dos itens 
expostos, instigam os participantes a exercitarem os sentidos para tentarem identificar os objetos. Aqui, reflete-se sobre a dependência da visão no como formadora de uma perspectiva de imagem e de realidade.

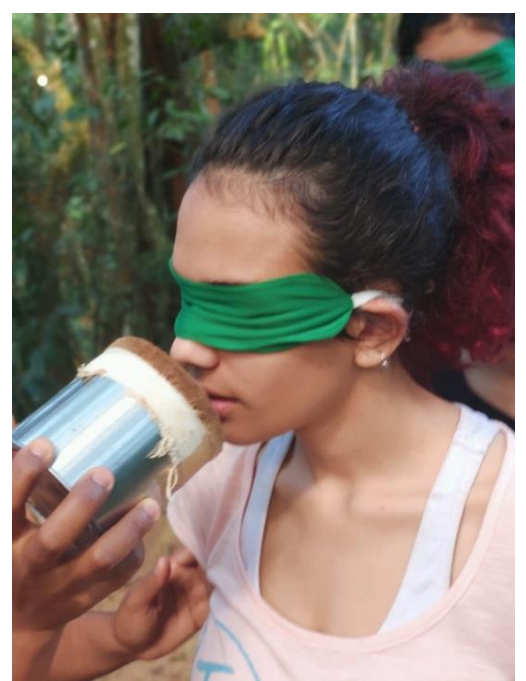

Figura 2: Explorando o olfato

Fonte: Elaborado pelos autores, 2019.

Os desafios continuam, e no segundo estágio, a corda passa a não estar mais em uma mesma altura (Figura 3), havendo necessidade de o participante se esforçar para se deslocar, tornando o ambiente menos cômodo, com descidas e subidas que exigem a exploração por meio da audição e tato junto ao solo ou nas árvores mais próximas. Aqui, a informação (antes visual) chega até os visitantes por outras formas, sendo aguçados os canais sensoriais do tato e da audição. Estimula-se o tato ativo, no qual a busca de informação se dá de modo intencional por meio do toque. Nesta esteira, estão envolvidos não só a pele e os tecidos subjacentes, mas “(...) receptores dos músculos e tendões, de maneira que o sistema perceptivo háptico capta a informação articulatória motora e de equilíbrio" (OCHAÍTA; ROSA, 1995, p.185).

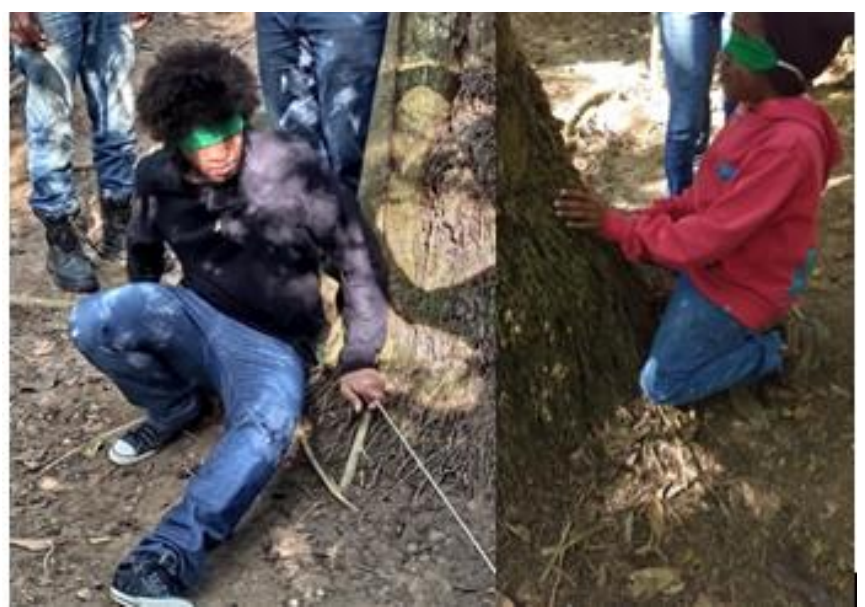

Figura 3: Exploração do local e experiências táteis Fonte: Elaborado pelos autores, 2019. 
O tato traz outra percepção da realidade, delineada pelos contornos, formas e texturas tridimensionais. Ao contrário da visão, que aproxima os valores do sujeito na construção da concepção de beleza a partir dos elementos convencionados socialmente como esteticamente belos, a percepção pelo tato nega esta dimensão e leva em consideração a percepção do objeto, remetendo à diversidade como paradigma e nesta cada coisa é importante. Por isso, todo tronco, folha, pedra, ou outro elemento que venha a ser tocado pelo visitante, tem sua beleza investigada por outros sentidos, não sendo percebida de modo restritivo pela visão (OLIVEIRA, 2002). São também lembradas, pelos monitores, as dificuldades que os obstáculos promovem sobre a locomoção, dificultando o trânsito das pessoas com deficiência, em especial nas ruas das cidades. Tal questão busca desenvolver a empatia e o colocar-se no lugar do outro.

No último estágio, a audição é ativada. Os visitantes são incitados a ouvir os sons naturais do ambiente como o vento, os pássaros e as folhas das copas das árvores. Aqui é possível refletir sobre o complexo equilíbrio que existe na floresta. Também se faz nesse momento, o uso de um aparelho de celular pelo qual, são reproduzidos sons de diversos animais, de cachoeira e da chuva. Caminhando para o final da atividade, o trajeto com a corda de apoio aos participantes é finalizado. Neste momento, o participante da trilha deve seguir ainda por alguns metros, somente orientados pela voz do monitor do Parque, sem o apoio da corda pela trilha. Essa etapa é vencida de forma individualizada, quando o participante é chamado pelo próprio nome e deve se conduzir seguindo o som do chamado.

A audição, por vezes é negligenciada pelas pessoas videntes, que utilizam muito menos esse sentido e muito mais a visão como fonte de informação e conhecimento. Nesta fase da Trilha, o visitante tem de fazer os ajustes, por meio de suas percepções, entre aquilo que imagina estar à frente e aquilo que chega pela fala do monitor que o direciona. Rabêllo (2003, p.78) afirma quando não podem enxergar, as pessoas "(...) se tornam extremamente sensíveis aos matizes de inflexão, de volume, de cadência, de ressonância e das várias intensidades dos sons das falas dos outros, que passam despercebidos rotineiramente". A atividade contribui assim, por meio da linguagem, das percepções táteis e cinestésicas para o conhecimento dos cenários, contribuindo para a função organizadora e planejadora da Educação Ambiental.

Por fim, a visão é restabelecida, para os participantes. A venda é retirada e ele se vê, diante de um espaço com a presença do barro e é convidado a ficar descalço, a pisar e a tocar com as mãos e pés na terra (Figura 4). Nos casos dos cegos, estes também seguem para o recinto que representa o retorno à raiz, em analogia à possibilidade de interagir plenamente com a natureza e integrar-se a ela. 


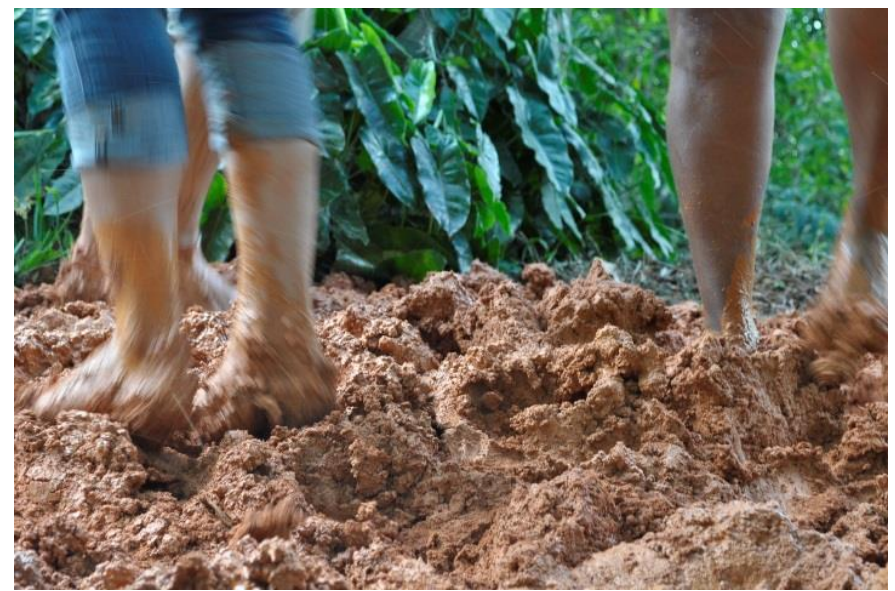

Figura 4: Pés descalços

Fonte: elaborado pelos autores, 2019.

Neste momento, os participantes são convidados a refletir e avaliar a atividade, relacionando a experiência com suas lembranças pessoais, da infância ou de itens da natureza como cheiro do café, gosto das frutas e sensações de toque na terra e tronco das árvores. Nos casos de haver grupos inclusivos, de cegos e videntes, é uma oportunidade para se discutir as dificuldades encontradas e desenvolver a empatia e a solidariedade. Os visitantes são provocados ainda, sobre o papel do ser humano na proteção do patrimônio ambiental, nas inúmeras formas de inclusão e deficiências que existem em virtude da falta de conhecimento sobre o meio ambiente e outros aspectos de sustentabilidade. Esse momento tem duração aproximada de 15 minutos, conforme o tamanho e a interação do grupo.

\section{Conclusões}

A Trilha dos Sentidos se tornou um atrativo com excelente procura. Em 2019, foi percorrida por 29 grupos (IEF, 2019). Atualmente, é uma grande oportunidade para a unidade de conservação atuar em Educação Ambiental, favorecendo com responsabilidade uma conexão individualizada com a natureza, explorando os diferentes sentidos e promovendo a mobilização para as questões do meio ambiente.

A experiência é exitosa por trazer outros insumos ao debate e processo de ensino-aprendizagem de alunos sem e com e é pautada numa estratégia de inclusão. Esta preocupação é importante porque a trajetória de muitas crianças com deficiência acaba sendo malsucedida devido à escassez de recursos para a instrumentalização dos professores, que promova o interesse e a plena participação nas atividades, e isso é particularmente pensado pelo parque ao construir suas atividades. Conquanto, a deficiência visual não constitua um empecilho direto para a aquisição de saber, o trabalho orientado nessa direção deve integrar conhecimentos e uso de recursos específicos em atividades 
concretas que favoreçam estratégias pedagógicas socializadoras e sensibilizadoras como a trilha.

Ainda, há que se considerar que a presença de um monitor do Parque acompanhando a trilha é fundamental por oferecer um atendimento personalizado e diferenciado, sem o qual, a experiência pode ser incompleta ou não permitir a abordagem ambientalista da proposta. Esta mediação tem colaborado para o fortalecimento de da ação, que espera beneficiar mudanças relacionadas ao comportamento ambiental dos participantes. Sensibilizar o público, possibilitando a formação de um agente crítico, útil para a construção de atitudes e valores ambientalmente responsáveis é uma meta da atividade.

Em 2019, uma nova versão foi inaugurada, uma "trilha acessível", na qual deficientes físicos e pessoas com mobilidade reduzida podem vivenciar as experiências em um percurso com trajeto adaptado. Esta representa mais uma ação, voltada para as questões referentes à necessidade de incluir, inovar e possibilitar o acesso à atividade de Educação Ambiental.

Por fim, é preciso considerar que a Trilha dos Sentidos dialoga com demandas contemporâneas: modelos de ensino-aprendizagem ambiental diferenciados, heterodoxos e compatíveis com diversos públicos. A ação do parque, que é um equipamento público privilegiado para a Educação Ambiental, reitera o caráter e a vocação das unidades de conservação como espaços de ensino e formação de uma nova mentalidade sustentável.

\section{Referências}

BAUMAN, Z. Nascidos em tempos líquidos. 1a. ed. Rio de Janeiro: Zahar, 2018.

BRASIL. Lei no 9795, de abril de 1999. Disponível em: < http://www.planalto.gov.br/ccivil 03/leis//9795.htm >. Acesso em: 26 jun. 2019.

BRASIL. Lei no 9985, de 18 de julho de 2000. Disponível em:< http://www.planalto.gov.br/ccivil 03/leis/l9985.htm>. Acesso em 26 jun. 2019

CAMARGO, E. P.; NARDI, R.; VERASZTO, E. V. A comunicação como barreira à inclusão de alunos com deficiência visual em aulas de óptica. Revista Brasileira de Ensino de Física, v.30, n.3, p. 3401-34013. 2008.

CEZARE, J. P. 2009. 177f. Conselhos municipais e governança: uma análise do Conselho de Representantes de Paranapiacaba e Parque Andreense do município de Santo André. São Paulo. Dissertação (Mestrado em Saúde Pública) - Cursod e Pós-Graduação em Saúde Pública, Universidade de São Paulo, Disponível em < https://www.teses.usp.br/teses/disponiveis/6/6134/tde21092009-152457/publico/JulianaPellegrini.pdf>. Acesso em 3 jul. 2019.

FREIRE. P. Pedagogia da autonomia. 3a . ed. São Paulo: Paz e Terra, 1996.

KISHIMOTO, T. M. Jogos, brinquedos, brincadeiras e educação. 6ª . ed. São Paulo: Cortez, 2002. 
INSTITUTO ESTADUAL DE FLORESTAS - IEF. Relatório Gerencial do Parque Estadual Mata do Limoeiro. IEF, 2018.

MORIN, E. Introdução ao pensamento complexo. 4a ${ }^{\mathrm{a}}$. ed. Porto Alegre: Sulina, 2011.

OCHAÍTA, E.; ROSA, A. Percepção, ação e conhecimento nas pessoas cegas. In: COLL, C.; PALÁCIOS, J.; MARCHESI, A. (Orgs.). Desenvolvimento psicológico e necessidades educativas especiais e a aprendizagem escolar. Porto Alegre: Artes Médicas, 1995.

OLIVEIRA, J. V. G. Do essencial invisível: arte e beleza entre os cegos. Rio de Janeiro: Revan/FAPERJ, 2002.

ONU. Report of the United Nations Conference on The Human Environment. Estocolmo: ONU, 1972. Disponível em: $<$ https://www.un.org/documents/ga/res/42/ares42-187.htm>. Acesso em: 16 abr. 2019.

ONU. Report of the World Commission on Environment and Development: our common future. New York: ONU. 1987. Disponivel em: $<$ https://sustainabledevelopment.un.org/content/documents/5987our-commonfuture.pdf>. Acesso em: 16 abr 2019.

QUIJANO, J. M. Inovação e estratégias para o desenvolvimento. In: VILLARES, F. Propriedade Intelectual: tensões entre o capital e a sociedade. São Paulo: Paz e Terra, 2007.

Rabêllo, R. S. 2003. 434f. Análise de um experimento de teatro-educação no Instituto de Cegos da Bahia: possibilidades de utilização da linguagem teatral por um grupo de adolescentes. São Paulo, Tese (doutorado em Educação) Universidade de São Paulo. Disponível em: < https://www.scielo.br/scielo.php?script=sci nlinks\&ref=000222\&pid=S1413$6538200800020000800070 \& \operatorname{lng}=\mathrm{pt}>$. Acesso 13. jun. 2019.

THIOLLENT, M. Metodologia da pesquisa-ação. 12a . ed. São Paulo: Cortez, 2003. 